\title{
Pathogenicity and Effects on Lymphoid Organs of Recent Moroccan Very Virulent Infectious Bursal Disease Virus in Broilers and SPF Chickens
}

Charifa DRISSI TOUZANI ( $\sim$ charifadrissi@gmail.com )

Institut Agronomique et Vétérinaire Hassan II: Institut Agronomique et Veterinaire Hassan II https://orcid.org/0000-0001-8301-7243

Imane MAAROUFI

IAV HASSAN II

Siham FELLAHI

IAV: Institut Agronomique et Veterinaire Hassan II

Ikhlass EL BERBRI

Pathology and Veterinary Public Health Department, Agronomy and Veterinary Institute Hassan II

Fatima-zohra SIKHT

IAV: Institut Agronomique et Veterinaire Hassan II

Ouafaa FASSI FIHRI

Pathology and Veterinary Public Health Department, Agronomy and Veterinary Institute Hassan II Noursaid TLIGUI

IAV: Institut Agronomique et Veterinaire Hassan II

Mohammed EL HOUADFI

IAV: Institut Agronomique et Veterinaire Hassan II

\section{Research Article}

Keywords: Avibirnavirus, vvIBDV, Pathogenicity, Lymphoid organs, Broilers, SPF chickens

Posted Date: October 26th, 2021

DOl: https://doi.org/10.21203/rs.3.rs-970270/v1

License: (c) (i) This work is licensed under a Creative Commons Attribution 4.0 International License.

Read Full License 


\section{Abstract}

The aim of the current study is to evaluate the pathogenicity of recent infectious bursal disease virus (IBDV) (1/chicken/Morocco/IB19/2017) genetically characterized as vvIBDV belonging to genogroup 3.

Two chicken lines, broiler and specific-pathogen-free (SPF) chickens, were inoculated by occulonasal route with $0.2 \mathrm{ml}$ of the $10^{5} \mathrm{EID}_{50} / \mathrm{ml}$ of viral solution of IB19 vVIBDV strain at 29 days of age. The experimental monitoring was carried out during 10 days post challenge (dpc).

The clinical signs stared on day 2 pc with maximum severity observed between 3 and $6 \mathrm{dpc}$. The total mortality rate reached $10 \%$ in broilers (group G1) and $93 \%$ in SPF (G3). The macroscopic lesions in broilers $\mathrm{G} 1$ was a marked hypertrophy of the bursa of Fabricius (BF) with slight haemorrhage observed between 2 to $4 \mathrm{dpc}$, followed by very pronounced atrophy observed on the $5 \mathrm{dpc}$. The post-mortem examinations of dead SPF birds (G3) revealed on 3 dpc very haemorrhagic BF with black cherry appearance in $80 \%$ of dead birds. The mean Bursa/Body Index (BBI) of challenged broilers (G1) showed a decrease of $46 \%$ on day 9 pc compared to broilers control group (G2) indicating bursal atrophy. The microscopic lesions found in the BF on $3 \mathrm{dpc}$ consisted mainly of inflammation with severe lymphoid depletion of the follicles. The evaluation of recent vvIBDV outbreak is very important to understand its epidemiology and will contribute to the efficient prevention and control of IBD.

\section{Introduction}

Infectious bursal disease, also called Gumboro disease, is an immunosuppressive disease affecting young chickens commonly between 3 to 6 weeks of age, causing acute depletion of B lymphocytes in the bursa of Fabricius (BF) leading to immunosuppression, increasing the susceptibility of the flock to secondary infections and vaccination failures [1, 2]. Infectious bursal disease virus is a nonenveloped RNA virus belonging to the Avibirnavirus genus within the Birnaviridae family[3, 4]. IBDV genome consist of double stranded RNA (dsRNA) divided into two segments, a larger segment A (3.3kb) and a smaller segment B (2.8 kb). The last segment encodes for VP1 (97kDa), the putative RNA-dependent RNA polymerase [5]. The segment A contains two Open Reader Frames (ORF), the smaller one (ORF 1) encodes for VP5 (21kDa) non-structural protein. The second ORF encodes for the polyprotein (pp) VP234, by autoproteolysis the pp is cleaved into a capsid protein VP3, a viral protease VP4 and VP2 an outer capsid protein that play a major role in the virulence of the virus [6-9]. VP2 involves the antigenic regions responsible for serotype specificity and production of neutralizing antibodies in infected chickens [10]. There are several strains of IBDV, classified according to their pathotype, serotype and genotype [11-13]. The pathotype is assessed through the study of the clinical signs, mortality, macroscopic and microscopic lesions. The severity of clinical signs and lesions depends on the chicken breed, and the pathogenicity of the IBDV strain and age of infection. Layer breeds, most notably the White Leghorn, are more sensitive to the disease [2]. Besides, very virulent (vv) pathotype of IBDV strains cause the most severe lesions in the BF, as well as marked lesions in other lymphoid organs and inducing $50-100 \%$ mortality rate in SPF chickens [14]. Clinically, the acute infection with vvIBDV is characterized by severe 
depression with ruffled feathers and white watery diarrhoea[15, 16]. The symptoms and mortality appear suddenly, usually at day $3 \mathrm{pc}$, peak and recede in 5 to $7 \mathrm{dpc}[2,16]$. However, the virulence of the IBDV strains varies greatly and can differ from their genotype [2]. The virulence nature of IBDV is very complex $[17,18]$. This is why the evaluation of IBDV virulence is very important to understand its epidemiology and contribute to the efficient prevention and control. vvIBDV genotype was detected in broilers flocks in different parts of Morocco, based on the molecular characterization of hypervariable region of VP2 [19]. Moroccan IBDV isolates belong to genogroup 3 according to the new classification proposed by [13]. Then, further investigations on full genome characterisation of Moroccan IBDV isolates confirms the circulation and spread in birds of a pure IBDV strains derived from a very virulent genotype of IBD viruses inducing high economic damage for the poultry industry [20]. Besides, the molecular investigations on both segments A and B of vvIBDV Moroccan isolate, showed the presence of exclusive markers of virulence associated to specific mutations which might enhance viral virulence[20].

The aim of the present study was to assess and evaluate the pathogenicity of a candidate strain of Moroccan vvIBDV genotypeand whether these mutations affect its virulence behaviour. An experimental pathogenicity study was conducted on broilers and SPF chickens using vvIBDV Moroccan strain as virus challenge. Thus, clinical signs, mortality, grosses and histologic lesions, morphometric measurements and viral load were investigated.

\section{Materials And Methods}

\section{Animals}

Fifty Cobb broilers chicks were raisedin poultry pens at Avian Pathology unit at Agronomy and Veterinary Institute Hassan II (Rabat, Morocco) from the age of 1 day old. At 1-day-old, blood samples were collected from 10 chicks and submitted for serological analysis, to determine the level of maternal antibodies against IBDV. The remaining 40 chicks were vaccinated against infectious bronchitis, Newcastle disease virus and H9N2 influenza virus following a standard vaccination schedule mimicking the field conditions (Table 1). In the other hand, Twenty-five SPF chicks were kindly obtained from $\mathrm{MCl}$ (Mohammedia, Morocco) at 5 days old and divided into 2 groups in separate pens at Avian Pathology Unit (Rabat, Morocco). The birds had free access to food and water. 
Table 1

Vaccination schedule for broilers chickens

\begin{tabular}{|lll|}
\hline Age of chicks (daysold) & Diseases & Vaccine Strain \\
\hline 4 & $\begin{array}{l}\text { Infectious bronchitis } \\
\text { Newcastle disease }\end{array}$ & Massachusett (H120) \\
& VG/GA \\
\hline 9 & Avian influenza & H9N2 Middle East inactivated \\
\hline 16 & Infectious bronchitis & IB88 \\
\hline
\end{tabular}

\section{Virus}

The challenge virus 1/chicken/Morocco/IB19/2017 (accession $N^{\circ}$. MK580160) was used in this study [20]. This virus had been isolated from IBD outbreak in broilers farm showing moderate mortality and haemorrhagic BF. Viral titer of the strain used in this study was $10^{5} \mathrm{EID}_{50} / \mathrm{ml}(50 \%$ embryo infective dose per millilitre).

\section{Experimental design}

Experiment 1. The Broilers chickens were divided into 2 groups. Group 1(G1) ( $n=30$ birds) were tagged and challenged at Day 29 of age by oculo-nasal routes with $10^{5} \mathrm{EID}_{50} / \mathrm{ml}$ of vvIBDV Moroccan strain. Group 2 (G2) ( $n=10$ birds), birds were kept as unchallenged control group. The clinical signs and mortality were recorded daily during 9 days post-challenge (dpc).

On day 1, 3, 5 and 7 pc, four chickens from $\mathrm{G} 1$ and one control from $\mathrm{G} 2$ were birds were randomly selected and sacrificed (euthanized). Weight and macroscopic lesions of sacrificed birds were recorded. Morphometric measurements (as described below) were carried out on BF, spleen and thymus. The collected bursa were divided into 2 pieces, one stored at $-20^{\circ} \mathrm{C}$ for molecular analyses. The second half was placed in 10\% neutral-buffered formalin for histopathological examinations. Samples from spleen, caecal tonsils, liver, kidneys, and thymus were collected for histopathological examinations. Cloacal swabs were collected on day $2,4,6,8$, and $9 \mathrm{pc}$ and stored at $-20^{\circ} \mathrm{C}$ for viral load in cloacal swabs. On day9 $\mathrm{pc}$, all the remaining chickens were humanly sacrificed, $\mathrm{BF}$ and other organs were collected.

Experiment 2. Twenty-five SPF chicks were divided into 2 groups: Challenged group G3 ( $n=15$ birds) and unchallenged group G4 ( $n=5$ birds). Blood samples from 5 chickens were taken before challenge to con $\square \mathrm{rm}$ the absence of antibodies against IBDV. At 29 days of age, birds were individually tagged. Only G3 was challenged with $10^{5} \mathrm{EID}_{50} / \mathrm{ml}$ of Moroccan vvIBDV strain via the oculo-nasal route $(0,2 \mathrm{ml}$ volume). G4 group was kept as a negative control. The clinical signs and mortality were monitored daily during $10 \mathrm{dpc}$. Bursa of birds dying during the acute phase of the disease were collected and divided on 
two half, one was stored at $-20^{\circ} \mathrm{C}$ for viral load and the second was placed in $10 \%$ neutral-buffered formalin for histopathological analyses.

\section{Clinical signs}

After challenge, birds of each group were examined individually for detection of any sign of IBD started from depression associated with prostration, ruffled feathers and white liquid diarrhoea with severe IBD signs.

\section{Microscopic lesions}

Histological sections were made and stained with haematoxylin-eosin, following conventional procedures. The microscopic lesions were described for BF, caeca tonsils, spleen, thymus, liver and kidneys for broilersand BF for SPF chickens. The lesions severity was scored for the BF, caeca tonsils, spleen and thymus.

For the BF, lesions were scored using the method of [21] as described [22, 23] : $0=$ no damage; $1=$ scattered lymphoid necrosis in a few follicles; $2=$ moderate lymphoid depletion in most of the bursal follicles, or isolated follicles with severe depletion; $3=$ severe lymphoid depletion in almost all of the bursal follicles, who appear pale and vacuolated, heterophil infiltration; 4=outlines of follicles remaining with few lymphocytes, glandular transformation, cysts, increase in interfollicular tissue, lymphoplasmatic infiltration; 5=complete loss of follicular architecture with fibroplasia.

For the caeca tonsils, lesions were scored using a simplified version of the method of [14] : $0=$ no damage; 1 = mild lymphoid depletion in some germinal centers; $2=$ moderate lymphoid depletion in some germinal centres; $3=$ severe lymphoid depletion in all germinal centres and the lamina propria.

For the spleen, lesions were scored using a modified version of the method of [24]: $0=$ no damage; $1=$ severe hyperemia without lymphoid depletion; $2=$ hyperplasia of the reticular cells; $3=$ marked hyperplasia of the reticular cells with lymphoid depletion; 4= severe lymphoid atrophy.

Finally, for the thymus, lesions were scored using the method of [14]: $0=$ no damage; $1=$ mild diffuse cortical atrophy (more than $50 \%$ of the cortex remains compared with control cortex); $2=$ moderate diffuse cortical atrophy (less than $50 \%$ of the cortex remains); $3=$ severe diffuse cortical atrophy (no cortex remains, or the corticomedullary junction is obscured).

\section{Morphometric measurements}

The morphometric measurements included the Organ/Body Ratio, the Bursa/Body Index and the volume of the BF concerned broilers. The Organ/Body Ratio was calculated for the BF, spleen, and thymus using a generalized version of the formula

$$
\text { Organ/Body Ratio }=\frac{\text { weight of the organ }(g)}{\text { weight of the chicken }(g)} \times 100
$$


The Bursa/Body Index was calculated using the formula cited by (25)

Bursa: Body Index $(\mathrm{BBI})=\frac{\text { Bursa/Body Ratio }(\mathrm{BBR}) \text { of challenged chicken }}{\text { Mean BBR of the control group }}$

The volume of the BF was calculated using the following formula ( $r$ is the radius of the BF):

$\mathrm{V}=\frac{4}{3} \times \pi \times \mathrm{r}^{3}$

\section{Quantification of IBDV using quantitative RT-PCR}

A preliminary qualitative real time RT-PCR was carried out to assess the cycle thresholds (CT) of the samples. The sample with the lowest CT (11.86) was then chosen as a standard for the quantitative real time RT-PCR.

RNA extraction. The virus preparation was carried out from the individual BF harvested and centrifuged and removed the supernatant for viral extraction [19]. The cloacal swabs and BF supernatants were processed using the MACHEREY-NAGEL viral RNA isolation kit (MACHEREY-NAGEL GmbH \& Co. KG, Düren, Germany), according to the manufacturer's instructions.

Real time reverse-Transcription PCR. A one-step real-time RT-PCR was carried out in an ABI Prism 7500 (Applied Biosystems, ThermoFisher SCIENTIFIC). The kit used for the reaction was a Bioline SensiFAST kit (Life Science Company). The primers and probes used as described by [25]. The reaction mixtures and the thermal cycling used in this study followed the protocol as described by [19].

Standard curve. A standard curve was made by serial 10 -fold dilutions after quantification of the total RNA of the standard sample using a NanoDrop spectrophotometer (Nanodrop technologies, Wilmington, DE). The standard curve was made using Microsoft Excel.

\section{Results}

\section{Clinical signs \& Mortality}

Experiment 1. The clinical signs of acute IBD, characterized by severe depression with prostration, ruffled feathers and white watery diarrhoea were observed. They appeared suddenly on day 3 pc, peaked from 3 to $6 \mathrm{dpc}$, and decreased at $7 \mathrm{dpc}$. Mortality occurred on day $4 \mathrm{pc}$ and reached $10 \%(2 / 20)$. Nor mortality was observed in negative control G2.

Experiment 2. Daily clinical observations of SPF chickens revealed the presence of prostration as early as 24 hours post challenge. At 48 hours post inoculation, some birds were reluctant to move, with ruffled feathers and white watery diarrhoea. The clinical signs get worse on 3 and $4 \mathrm{dpc}$. Morbidity reached respectively 74 and $100 \%(11 / 15-6 / 6)$ on 3 and $4 \mathrm{dpc}$. However, the mortality rate reached respectively 
$60 \%(9 / 15)$ on day $3 \mathrm{pc}$ and $83 \%$ (5/6) on day $4 \mathrm{pc}$ for challenged group (G3). No clinical signs were detected in birds of negative control group (G4 Group).

\section{Postmortem examination}

Experiment 1.The most macroscopic lesions were observed on BF were characterized by petechial haemorrhages into bursal mucosae as well as oedema. These lesions peaked in severity on day 4 pc. Bursal atrophy was the predominant lesion from day 7 to $9 \mathrm{pc}$. After $5 \mathrm{dpc}$, most of BF became small and yellowish. Splenic congestion with splenomegaly was observed from 3dpc, peaked between 4 to $7 \mathrm{dpc}$ and decreased on $9 \mathrm{dpc}$. Thymic congestion lesions appeared on day $4 \mathrm{pc}$.

Experiment 2. The post-mortem examination carried out on birds died on day 3 and 4 pc (14/15) and on one remaining chicken sacrificed at day $10 \mathrm{pc}$. The most frequent lesions observed in $80 \%$ of birds were severe haemorrhagic BF and petechial haemorrhages in thigh and breast muscles (Figure 1). Other lesions were observed such as splenomegaly and enlargement of kidney in $60 \%$ of the birds. No gross lesions were detected in G4 group.

\section{Morphometric measurements}

Volume of the Bursa of Fabricius. The volume of the BF decreased severely in challenged broilers (G1), varying approximately from $7 \mathrm{~cm}^{3}$ to $2.5 \mathrm{~cm}^{3}$. In contrast, the bursa volume in control broilers (G2) increased moderately (Figure 2A).

Bursa Body Ratio (BBR) and Bursa Body Index (BBI). Both the BBR and the BBI decreased severely in challenged broilers (G1). The first one BBR decreased from 0.225 to 0.075 compared to unchallenged broilers (G2), the BBR increased slightly from 0.200 to 0.250 (Figure 2B). Furthermore, the BBI revealed a distinct regression compared to unchallenged broilers (G2) with value of 0.54 and 1 respectively (Figure 3).

Spleen Body Ratio (SBR). The data revealed that challenged broilers (G1)had a significant increase of SBR compared to control group (G2) confirming the splenomegaly observations (Figure 2B).

Thymus Body Ratio (TBR). The results showed pronounced reduction of TBR in challenged broilers (G1), suggesting a thymic atrophy, whereas in control chickens (G2), an increase of TBR was revealed (Figure 2B).

\section{Microscopic lesions}

\section{Bursa of Fabricius.}

Experiment 1.0n day $1 \mathrm{pc}$, no microscopic lesions were observed. An acute inflammation was however present on $3 \mathrm{dpc}$, characterized by an oedema of the tunica muscularis and the tunica mucosa, severe heterophil infiltration in the stroma and follicles, as well as severe lymphoid depletion of the follicles. Many follicles also contained cysts. The inflammation peaked in severity on 4dpc (Figure 4A), and associated by vascular congestion in the stroma. The lining epithelium was also very waved. 
On $5 \mathrm{dpc}$, a moderate to severe lymphoplasmacytic infiltration could be observed in the tunica muscularis. Some follicles had undergone metaplasia of the reticular epithelium, which had turned into pseudostratified epithelium. The lining epithelium was corrugated and hyperplastic.

The lymphoplasmacytic infiltration had extended to the stroma on $7 \mathrm{dpc}$, and the tunica muscularis had undergone fibroplasia. The metaplasia of the reticular epithelium was found in most of the follicles, which were almost totally depleted and contained large cysts.

Finally, on $9 \mathrm{dpc}$, the lesions found on $7 \mathrm{dpc}$ had increased in severity (Figure 4B), and in some chickens, both the tunica muscularis and the stroma had undergone severe fibroplasia, with only sparse follicles remaining, who had completely lost their architecture. The hyperplasia of the lining epithelium was most severe at the apex of the plicae (Figure 4C), and multiple cysts of varying sizes were found in the lining epithelium. The mean lesion score gradually increased until reaching 3.75 at $9 \mathrm{dpc}$ (Table 2). No microscopic lesions were observed in BF of control broilers group (G2), the BF follicles appears perfectly normal with heavily lymphocytes populations (Figure 4D).

Table 2

Mean lesion scores of histological sections of lymphoid organs in challenged broiler (G1)

\begin{tabular}{|lllllll|}
\hline \multirow{2}{*}{ Organ } & \multicolumn{7}{l|}{ Mean lesion scores at days post-challenge } \\
\cline { 2 - 7 } & $\mathbf{1}$ & $\mathbf{3}$ & $\mathbf{4}$ & $\mathbf{5}$ & $\mathbf{7}$ & $\mathbf{9}$ \\
\hline Bursa of Fabricius & $0 / 5$ & $2 / 5$ & $3 / 5$ & $2.67 / 5$ & $3.33 / 5$ & $3.75 / 5$ \\
\hline Spleen & $0.33 / 4$ & $2 / 4$ & $-*$ & $2 / 4$ & $2.5 / 4$ & $1.6 / 4$ \\
\hline Thymus & $0 / 3$ & $0 / 3$ & $3 / 3$ & $0 / 3$ & $0.25 / 3$ & $0 / 3$ \\
\hline Caecal Tonsils & $0 / 3$ & $0 / 3$ & $3 / 3$ & $2 / 3$ & $0 / 3$ & $0 / 3$ \\
\hline *Unfortunately, spleen samples for day 4 pi were damaged and scores could not be recorded. \\
\hline
\end{tabular}

Experiment 2. The microscopic lesions revealed the degeneration and necrosis of lymphocytes in the cortex of bursa follicles. Lymphocytes were replaced by heterophils. In many follicles, oedema and enlargement in interfollicular areas were observed. Haemorrhages were also present in the cortex and medullar regions (Figure 5A). In some follicles, vacuolisations and necrosis in medullary area were found. Bursa lesions were significantly more severe in SPF challenged group (G3), the mean bursa lesion score was found on bursa of dead SPF chickens (14/15) at 3 and 4 dpc reached 3 value. In negative SFP control group (G4), no hitological lesions were detected and the BF follicles showed high lymphocytes populations (Figure 5B).

Spleen.The first lesions observed in the spleen appeared on day $3 \mathrm{pc}$, and were characterized by severe hyperplasia of the reticular cells, as well as severe hyperaemia of the red pulp (Figure 6A). On 4dpc, macrophages were surrounding the small blood vessels, and from 5 to $7 \mathrm{dpc}$, the periarteriolar lymphoid 
sheaths were depleted, as well as the germinal centers, seen in smaller numbers. Lymphoid repopulation was observed on $9 \mathrm{dpc}$, and germinal centers were reactive and seen in increased numbers. The mean lesion score was between 2 and 2.5 from3 to $7 \mathrm{dpc}$, then decreased (Table 2).

Thymus.A severe hyperaemia and haemorrhages were observed on day $4 \mathrm{pc}$. There was a severe lymphoid depletion of the cortex (Figure 6B), necrosis of the medulla (Figure 6C), and the corticomedullary junction was not apparent. On day $5 \mathrm{pc}$, hyperplasia of the reticular cells could be observed. Finally, from 7dpc onwards, only hyperaemia and haemorrhages could be seen. The mean lesion score for the thymus was 3 and reached the maximum at day 4 pc (Table 2).

Caeca tonsils. Lesions in the tonsils appeared at $3 \mathrm{dpc}$ and were characterized by a severe lymphoid depletion of the lamina propria and a severe necrosis of the germinal centers. These were reduced to small masses of necrotic debris (Figure 6D). On day $5 \mathrm{pc}$, several germinal centers were moderately to severely depleted, without necrosis. The lamina propria had been partially to completely repopulated. On day $7 \mathrm{pc}$, the germinal centershad been repopulated. Some of them contained large and mildly basophilic lymphoid cells. Finally, on day 9 pc, no differences could be detected between the control group (G4) and the challenged group (G1). The mean lesion score reached 3 at $4 \mathrm{dpc}$ and decreased at $5 \mathrm{dpc}$ (Table 2).

\section{Viral load in the bursa of Fabricius and viral excretion in the cloacal swabs}

\section{Bursa of Fabricius}

The virus detection by qRT-PCR from BF in challengedbroilers chickens (G1) revealed that viral load was rather low on day $1 \mathrm{pc}$ and increased on day $3 \mathrm{pc}$ to reach13.5 threshold cycle (Ct). It remained high during the following days of the experiment, with a peak $(\mathrm{Ct}=11.8)$ on day3 and $5 \mathrm{pc}$ (Figure 7A). The viral load gradually decreases in the end of the experiment until the minimum $\mathrm{Ct}=29.5$ was found at $9 \mathrm{dpc}$. In the other Group, the large majority of SPF birds were found dead at 3 and $4 \mathrm{dpc}(14 / 15)$, the viral load in this Group was very high reached Ct values between 12.9 and 18.9.

In survivor SPF bird (G3), the level of virus detection was approximately low at $10 \mathrm{dpc}(\mathrm{Ct}=21.8)$.

\section{Viral excretion in the cloacal swabs}

In commercial broilers (G1), the viral excretion was rather low on day $1 \mathrm{pc}(\mathrm{Ct}=29.3)$, and was fairly high reached a peak at $4 \mathrm{dpc} \mathrm{Ct}=21$. At day $8 \mathrm{pc}$ it had decreased significantly $(\mathrm{Ct}=25.7)$ and remained low at 9dpc (Ct= 28.7) (Figure 7B).

\section{Discussion}

Infectious bursal disease is among the most economically viral disease affecting poultry industry in the world. IBDV has a different range of virulence, and in particular vvIBDV strains being responsible for the high failures from mortalities and decreased performances. Recently in Morocco, molecular 
characterisation of full genome IBDV revealed the presence and spread in poultry flocks, the vvIBDV genotype strains including all genetic markers of virulence associated to some amino acids specific to Moroccan IBDV isolates [20]. However, the study of viral virulence evolution of Moroccan vvIBDV isolate would being of great interest to correlate the genotype to the pathotype of the virus strains. In this study, we tried to determine and to evaluate the pathogenicity of one candidate strain of a recent Moroccan vvIBDV designated 1/chicken/Morocco/IB19/2017 (accession no. MK580160 and MK580164) by assessing the clinical signs, mortality rate, the macroscopic and microscopic lesions of different lymphoid organs in commercial broilers (G1) under experimental conditions. The objective of the second experiment was to reproduce the Infectious Bursal Disease in light breed SPF chickens in which the mortality rate could reached $100 \%$ [22]. Using SPF chickens is considered as the standard model to assess the pathogenicity of IBDV.

The typical clinical signs of acute IBD including depression, prostration, ruffled feathers and watery or white diarrhoea were observed in both experiments and were similar to those previously described by (27) for acute infectious bursal disease. The mortality occurred at $4 \mathrm{dpc}$ for broilers (G1) reached $10 \%$ which is very low in comparison to SPF chickens where the mortality appeared at 3 to $5 \mathrm{dpc}$ and reached $84 \%$ at 5 days. Therefore, the mortality rate in SPF chickens (G3) is eight time higher than the mortality in broilers (G1), this can be explained by the genetic sensibility of light breed chickens to infection with very virulent IBD viruses than heavy breed as it has been reported in several studies [26]. The mortality rate (10\%) in broilers(G1) found in this study was similar to the rate reported by $[22,27]$ for vvIBDV field outbreaks in broilers. These authors reported respectively mortality rates comprised between $5-15 \%$ and $10-25 \%$.

The Gross lesions observed on SPF chickens (G3) found in our work were more severe than the macroscopic lesions observed in the commercial broilers (G1), specially the BF of SPF (G3) was very haemorrhagic giving the appearance of black cherry observed in most of dead birds (G3). Nevertheless, the macroscopic lesions in commercial broilers (G1) dominated by small yellowish Bursae, this is similar to previous descriptions of the disease by $[2,12]$. Furthermore, the volume of the BF decreased in challenged broilers (G1), while it moderately increased in control chickens (G2) corresponding to the normal growth of the BF as demonstrated by [28]. We observed significant regression in Bursa Body Ratio in challenged broilers $(\mathrm{G} 1)$, similarly to the observations of $[14,17]$ in their studies of the impact of vvIBDV strains in Bursa Body Ratio parameter.

According to [29], a mean Bursa/Body Index inferior to 0.70 in broilers indicates bursal atrophy. The mean Bursa/Body Index in our experiment on broilers (G1)was 0.54 , indicating a severe bursal atrophy.

The Spleen Body Ratio increased in challenged broilers (G1), which mean the presence of splenomegaly at 5, 7 and $9 \mathrm{dpc}$, this has also been described by [17] for the vvIBDV 92/04 strain. The Thymus Body Ratio decreased severely in challenged broilers (G1), which could be attributed to thymic atrophy. This observation had also been made by [14] in their study using Japanese vvIBDV strains. However, thymic microscopic lesions of broilers (G1) were very transient, and only visible in chickens that had died, in contrast to the severe thymic lesions observed in SPF chickens described by $[1,30]$. 
The histological lesions of the BF of challenged broilers (G1) did not show lymphoid regeneration at 9 $\mathrm{dpc}$, which has been described by [27] as typical of infections by vvIBDV strains higher virulence and the mean lesion score was 3.75. This score is similar to scores obtained by [31] (3.3) for 90-11 Japanese vvIBDV strain, as well as those obtained by [22] (3.8) for 849 VB European vvIBDV strain. In addition, the mean lesion scores for the spleen, cecae tonsils and thymus were also similar to the scores obtained in previous studies of very virulent strains from Japan and the Netherlands [14, 32, 33].

Regarding the liver, periportal lymphoid infiltrations have been previously described for infectious bursal disease by [34]. In the kidneys, degeneration of tubular epithelial cells was observed in our study, these lesions were also found in sacrificed chickens after $7 \mathrm{dpc}$, this could be explained by a vvIBDV pathotype of Moroccan strain used in this study.

Finally, the viral load in the BF and viral excretion during an IBDV infection have not been extensively studied before. Li and Co-authors [35] assessed the viral load in the BF and viral excretion via RT-PCR relative quantification, following an experimental infection with the vvIBDV European strain DK01. At $3 \mathrm{dpc}$, the relative viral load in our study was over 3 times higher than the value obtained by the same authors using DK01 as vvIBDV challenged strain. This suggests a higher replication of Moroccan virus in $\mathrm{BF}$, which clearly indicate a high virulence of Moroccan vvIBD virus used in this study.

The results of the current study showed the high pathogenic potential of Moroccan IBD virus recently isolated and genetically characterized as very virulent virus based on both genome segments and confirm the observations previously reported that SPF light breed chickens are more susceptible to vvIBDV infection than broilers[26]. However, the differences in susceptibility to infection with IBDV based on genetic variations of SPF chickens lines [36]. Nielsen and Collaborators [37] reported high susceptibility to the infection with IBDV was found in layers chickens vs. the broilers. Further studies of vaccines protection are needed to evaluate the level of protection conferred by available vaccines used in the country against the recent Moroccan vvIBDV isolates.

In conclusion, the vvIBDV Moroccan strain used in this study exhibited a very virulent pathotype according to very virulent genotype finding based on characterization of both genome segments. The pathogenicity of Moroccan vvIBDV is increased when both genome segments A and B are found as very virulent [38]. This synergy between the vv segments $A$ and $B$ generate high pathogenicity of the virus [39].

\section{Abbreviations}

$\mathrm{BBI}=$ Bursa Body Index; BBR=Bursa Body Ratio; BF=Bursa of Fabricious; $\mathrm{CT}=$ =cycle thresholds; dpc=days post challenge; dsRNA=double stranded RNA; EID50/ml=50\% embryo infective dose per millilitre; G1=challenged broiler group; G2=broilers control group; G3=challenged SPF group; IBDV=Infectious

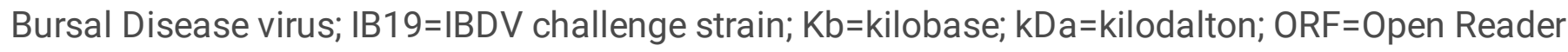
Frames; $\mathrm{pp}=$ polyprotein; SPF=Specific Pathogen Free; SBR=Spleen Body Ratio TBR =Thymus Body Ratio; $\mathrm{vv}=\mathrm{very}$ virulent. 


\section{Declarations}

\section{Acknowledgment}

This work was funded by AVIAMED project through the ARIMNet2 2015 Call by the following funding agencies: Ministry of Higher Education, Scientifc Research and Professional Training of Morocco (MESRSFC) and Italian Ministry of Agricultural, Food and Forestry Policies (MIPAAF). ARIMNet2 (ERANET) has received funding from the European Union's Seventh Framework Programme for research, technological development and demonstration under grant agreement no. 618127.

\section{Competing interests}

The authors declare no conflict of interest.

\section{Availability of data and materials}

Data supporting the conclusions of this article are presented in the manuscript.

\section{Code availability}

Not applicable.

\section{Disclosure Statement}

All authors declare no conflict of interest.

\section{Compliance with Ethical Standards}

All animal experiments procedures were managed in exact accordance with European and French legislations on laboratory animal care and use (French Decree2001-464 and European Directive CEE86/609) and animal protocolsapproved by the Ethics Committee "Sciences et santéanimale," committee number 115. The animals were kept in within the animalfacilities (biosafety level 2) of the Agronomy and Veterinary Institute Hassan II.

\section{References}

1. Sharma J (2000) Infectious bursal disease virus of chickens: pathogenesis and immunosuppression. Developmental \& Comparative Immunology 24:223-235. https://doi.org/10.1016/S0145305X(99)00074-9

2. Eterradossi N, Saif YM (2020) Infectious Bursal Disease. In: Swayne DE, Boulianne M, Logue CM, et al (eds) Diseases of Poultry, 1st ed. Wiley, pp 257-283

3. Kibenge FSB, Dhillon AS, Russell RG (1988) Biochemistry and Immunology of Infectious Bursal Disease Virus. Journal of General Virology 69:1757-1775. https://doi.org/10.1099/0022-1317-69-81757 
4. International Committee on Taxonomy of Viruses, King AMQ (2012) Virus taxonomy: classification and nomenclature of viruses: ninth report of the International Committee on Taxonomy of Viruses. Academic Press, London; Waltham, MA

5. von Einem UI, Gorbalenya AE, Schirrmeier $\mathrm{H}$, et al (2004) VP1 of infectious bursal disease virus is an RNA-dependent RNA polymerase. Journal of General Virology 85:2221-2229. https://doi.org/10.1099/vir.0.19772-0

6. Jagadish MN, Staton VJ, Hudson PJ, Azad AA (1988) Birnavirus precursor polyprotein is processed in Escherichia coli by its own virus-encoded polypeptide. J Virol 62:1084-1087

7. Mundt E (1999) Tissue culture infectivity of different strains of infectious bursal disease virus is determined by distinct amino acids in VP2. Journal of General Virology 80:2067-2076. https://doi.org/10.1099/0022-1317-80-8-2067

8. Birghan C, Mundt E, Gorbalenya AE (2000) A non-canonical lon proteinase lacking the ATPase domain employs the ser-Lys catalytic dyad to exercise broad control over the life cycle of a doublestranded RNA virus. EMBO J 19:114-123. https://doi.org/10.1093/emboj/19.1.114

9. Lejal N, Da Costa B, Huet JC, Delmas B (2000) Role of Ser-652 and Lys-692 in the protease activity of infectious bursal disease virus VP4 and identification of its substrate cleavage sites. J Gen Virol 81:983-992. https://doi.org/10.1099/0022-1317-81-4-983

10. Fahey KJ, Erny K, Crooks J (1989) A conformational immunogen on VP-2 of infectious bursal disease virus that induces virus-neutralizing antibodies that passively protect chickens. J Gen Virol 70 ( Pt 6):1473-1481. https://doi.org/10.1099/0022-1317-70-6-1473

11. McFerran JB, McNulty MS, McKillop ER, et al (1980) Isolation and serological studies with infectious bursal disease viruses from fowl, turkeys and ducks: demonstration of a second serotype. Avian Pathol 9:395-404. https://doi.org/10.1080/03079458008418423

12. Berg TP (2000) Acute infectious bursal disease in poultry: a review. Avian Pathol 29:175-194. https://doi.org/10.1080/03079450050045431

13. Michel LO, Jackwood DJ (2017) Classification of infectious bursal disease virus into genogroups. Archives of Virology 162:3661-3670. https://doi.org/10.1007/s00705-017-3500-4

14. Tanimura N, Tsukamoto K, Nakamura K, et al (1995) Association between pathogenicity of infectious bursal disease virus and viral antigen distribution detected by immunohistochemistry. Avian Dis 39:9-20

15. Chettle N, Stuart J, Wyeth $P$ (1989) Outbreak of virulent infectious bursal disease in East Anglia. Veterinary Record 125:271-272. https://doi.org/10.1136/vr.125.10.271

16. Cosgrove AS (1962) An Apparently New Disease of Chickens: Avian Nephrosis. Avian Diseases 6:385. https://doi.org/10.2307/1587909

17. Hoque MM, Omar AR, Chong LK, et al (2001) Pathogenicity of Sspl-positive infectious bursal disease virus and molecular characterization of the VP2 hypervariable region. Avian Pathol 30:369-380. https://doi.org/10.1080/03079450120066377 
18. Pikuła A, Lisowska A, Jasik A, Śmietanka K (2018) Identification and assessment of virulence of a natural reassortant of infectious bursal disease virus. Vet Res 49:89. https://doi.org/10.1186/s13567-018-0586-y

19. Drissi Touzani C, Fellahi S, Gaboun F, et al (2019) Molecular characterization and phylogenetic analysis of very virulent infectious bursal disease virus circulating in Morocco during 2016-2017. Arch Virol 164:381-390. https://doi.org/10.1007/s00705-018-4076-3

20. Drissi Touzani C, Fellahi S, Fassi Fihri O, et al (2020) Complete genome analysis and time scale evolution of very virulent infectious bursal disease viruses isolated from recent outbreaks in Morocco. Infection, Genetics and Evolution 77:104097. https://doi.org/10.1016/j.meegid.2019.104097

21. Muskett JC, Hopkins IG, Edwards KR, Thornton DH (1979) Comparison of two infectious bursal disease vaccine strains: efficacy and potential hazards in susceptible and maternally immune birds. Vet Rec 104:332-334. https://doi.org/10.1136/vr.104.15.332

22. Van den Berg TP, Gonze M, Meulemans G (1991) Acute infectious bursal disease in poultry: Isolation and characterisation of a highly virulent strain. Avian Pathology 20:133-143. https://doi.org/10.1080/03079459108418748

23. Reddy YK, Muralimanohar B, Koteeswaran A (2008) Bursal Lesion Scoring for the Assessment of Severity of Infectious Bursal Disease. Tamil Nadu Journal of Veterinary and Animal Sciences 4:2528

24. Halouzka R, Jurajda V (1991) Morphological Expression of Immunosuppression in Poultry. Acta Vet Brno 60:271-276. https://doi.org/10.2754/avb199160030271

25. Tomás G, Hernández M, Marandino A, et al (2012) Development and validation of a TaqMan-MGB real-time RT-PCR assay for simultaneous detection and characterization of infectious bursal disease virus. Journal of Virological Methods 185:101-107. https://doi.org/10.1016/j.jviromet.2012.06.012

26. Silva MS e, Rissi DR, Swayne DE (2016) Very Virulent Infectious Bursal Disease Virus Produces MoreSevere Disease and Lesions in Specific-Pathogen-Free (SPF) Leghorns Than in SPF Broiler Chickens. Avian Diseases 60:63-66. https://doi.org/10.1637/11230-070615-ResNote.1

27. Ignjatovic J (2004) Very virulent infectious bursal disease virus. Australia and New Zealand Standard Diagnostic Procedures 6

28. Cazaban C, Majo Masferrer N, Dolz Pascual R, et al (2015) Proposed bursa of fabricius weight to body weight ratio standard in commercial broilers. Poultry Science 94:2088-2093. https://doi.org/10.3382/ps/pev230

29. Lucio B, Hitchner SB (1979) Infectious Bursal Disease Emulsified Vaccine: Effect upon NeutralizingAntibody Levels in the Dam and Subsequent Protection of the Progeny. Avian Diseases 23:466-478. https://doi.org/10.2307/1589577

30. Inoue M, Fukuda M, Miyano K (1994) Thymic lesions in chicken infected with infectious bursal disease virus. Avian Dis 38:839-846 
31. Nakamura T, Otaki Y, Nunoya T (1992) Immunosuppressive Effect of a Highly Virulent Infectious Bursal Disease Virus Isolated in Japan. Avian Diseases 36:891-896. https://doi.org/10.2307/1591547

32. Nunoya T, Otaki Y, Tajima M, et al (1992) Occurrence of acute infectious bursal disease with high mortality in Japan and pathogenicity of field isolates in specific-pathogen-free chickens. Avian Dis 36:597-609

33. Hiraga M, Nunoya T, Otaki Y, et al (1994) Pathogenesis of highly virulent infectious bursal disease virus infection in intact and bursectomized chickens. J Vet Med Sci 56:1057-1063. https://doi.org/10.1292/jvms.56.1057

34. Ley DH, Yamamoto R, Bickford AA (1983) The pathogenesis of infectious bursal disease: serologic, histopathologic, and clinical chemical observations. Avian Dis 27:1060-1085

35. Li YP, Handberg KJ, Kabell S, et al (2007) Relative quantification and detection of different types of infectious bursal disease virus in bursa of Fabricius and cloacal swabs using real time RT-PCR SYBR green technology. Research in Veterinary Science 82:126-133.

https://doi.org/10.1016/j.rvsc.2006.03.002

36. Bumstead N, Reece RL, Cook JK (1993) Genetic differences in susceptibility of chicken lines to infection with infectious bursal disease virus. Poult Sci 72:403-410.

https://doi.org/10.3382/ps.0720403

37. Inflammatory response of different chicken lines and B haplotypes to infection with infectious bursal disease virus: Avian Pathology: Vol 27, No 2. https://www.tandfonline.com/doi/abs/10.1080/03079459808419321. Accessed 16 Aug 2021

38. Le Nouën C, Rivallan G, Toquin D, et al (2006) Very virulent infectious bursal disease virus: reduced pathogenicity in a rare natural segment-B-reassorted isolate. J Gen Virol 87:209-216. https://doi.org/10.1099/vir.0.81184-0

39. Jackwood DJ, Stoute ST, Crossley BM (2016) Pathogenicity of Genome Reassortant Infectious Bursal Disease Viruses in Chickens and Turkeys. Avian Dis 60:765-772. https://doi.org/10.1637/11409-031116-Reg

\section{Supplemental Figures}

Supplemental Figures 1 and 2 are not available with this version.

\section{Figures}




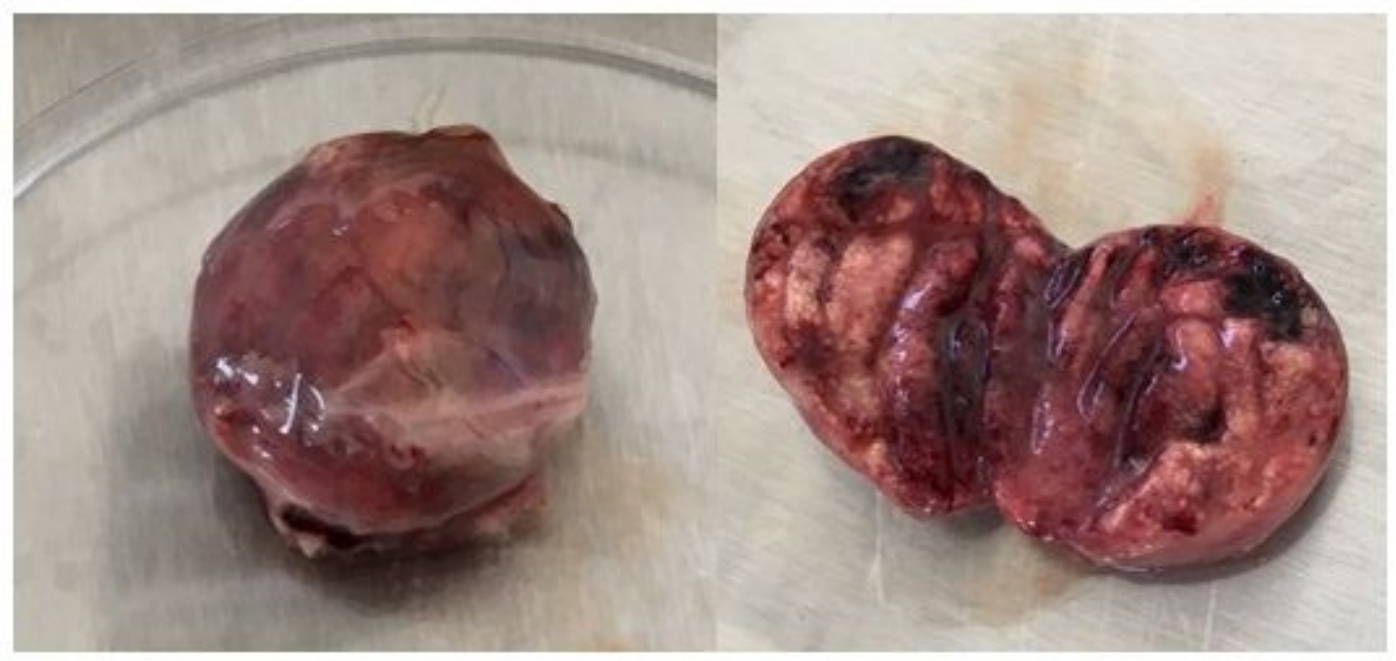

\section{Figure 1}

Bursa of Fabricius of challenged SPF chicken (G3) at $3 \mathrm{dpc}$ (black cherry) (left picture); Internal view of BF of challenged SPF chicken (right picture).

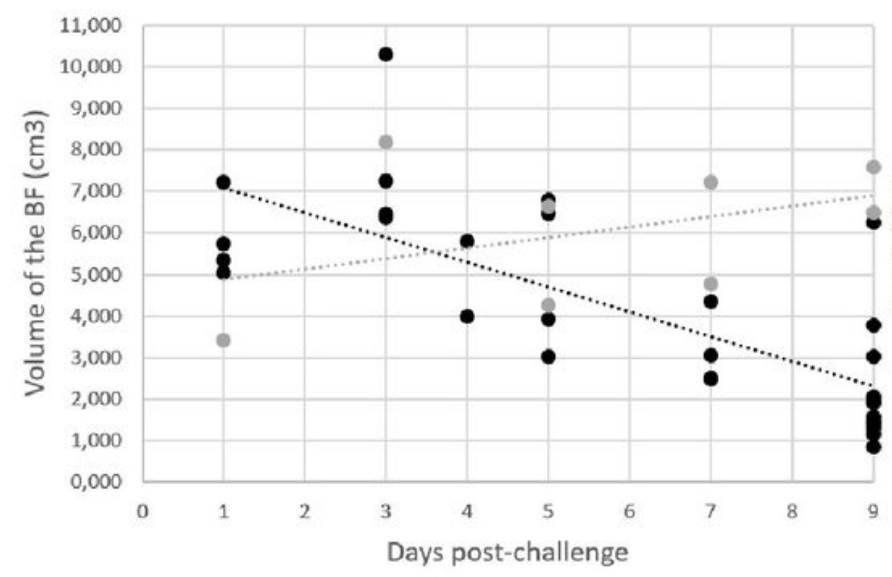

- Challenged chickens

- Control Chickens

. Trendline (Control Chickens)

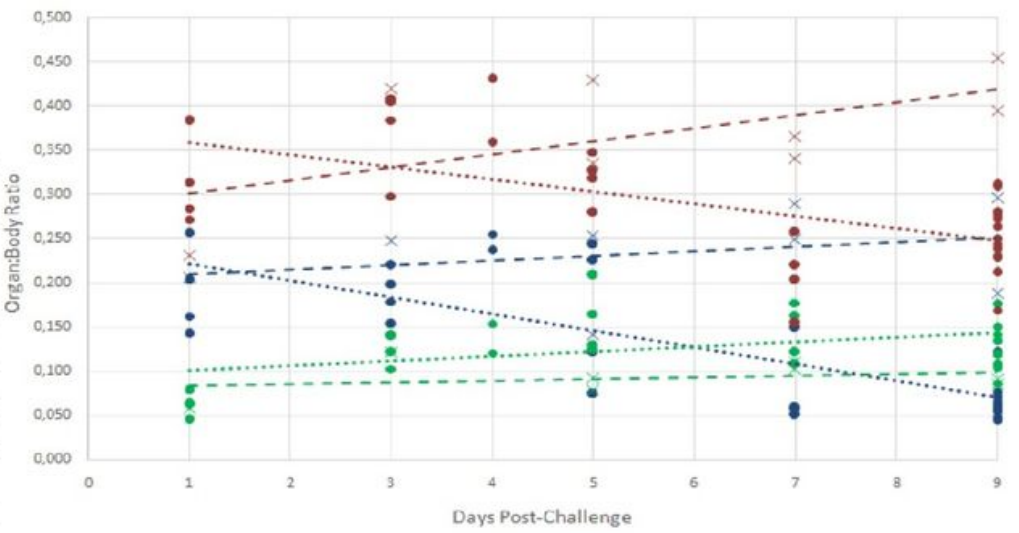

$\times$ Bursa.Bodr Ratio (Control Oickens) Spleen.Body Ratio(Contul Chichens) - Timatine (Burso fout rotio (Contris)

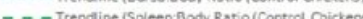

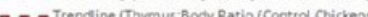

\section{Figure 2}

2A. Volume of Bursa of Fabricius for challenged and unchallenged broilers(G2)(left picture). 2B. Organ body ratio for challenged (G1) and unchallenged broilers(G2) (right picture). 


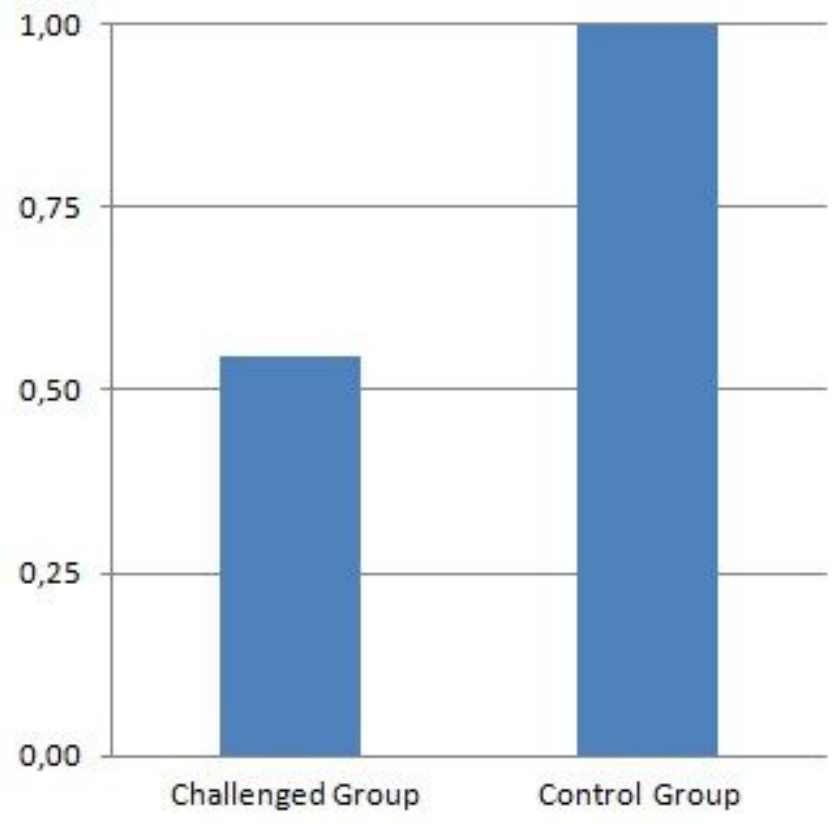

- Mean Bursa:Body Index

Figure 3

Mean Bursa Body Index of challenged and unchallenged broilers(G2). 


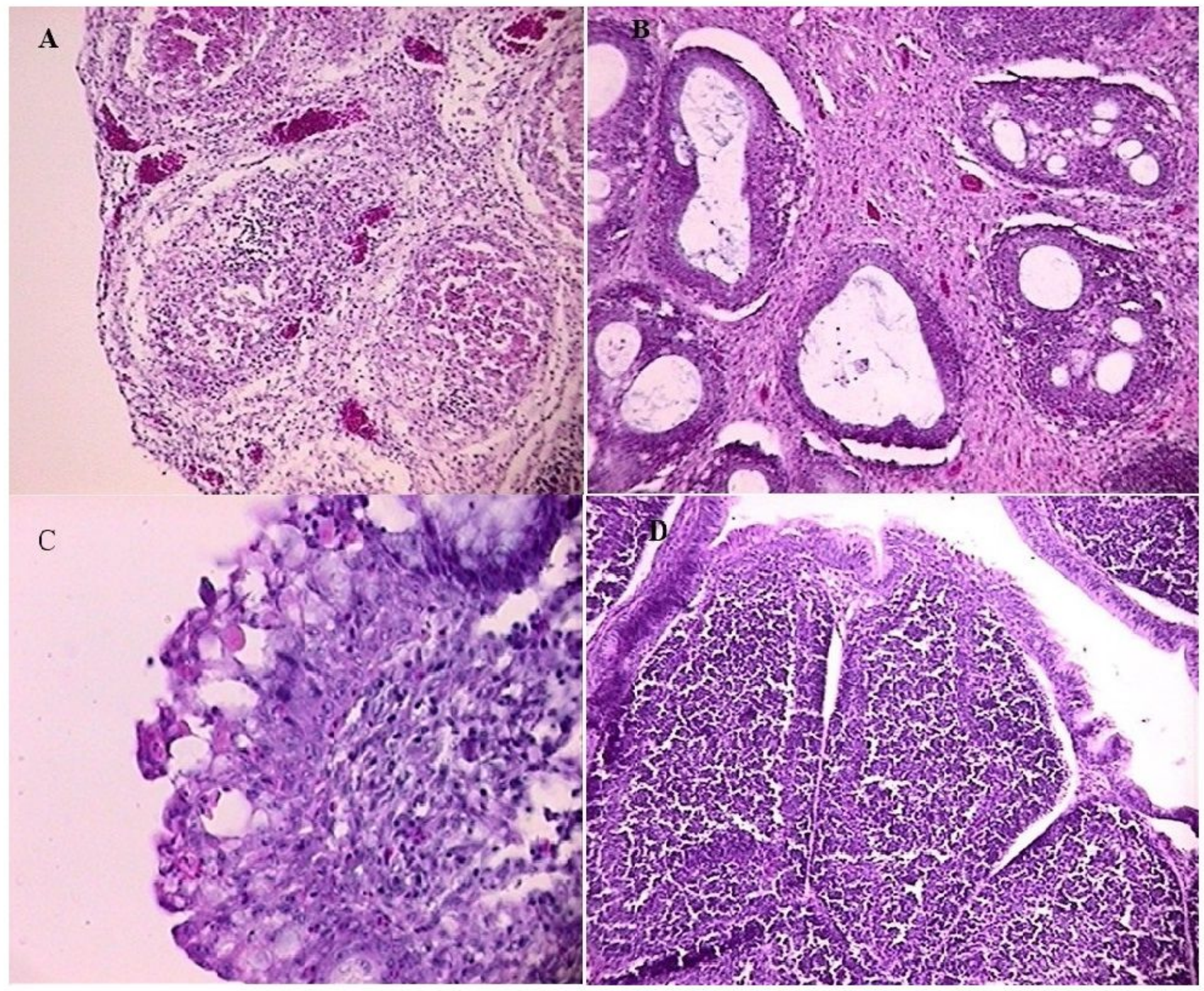

Figure 4

4A. Acute inflammation of the tunica mucosa with severe heterophil infiltration, lymphoid depletion of the follicles, and intrafollicular cysts filled with necrotic debris. Lesion score:3. Day 4 pc. H\&E, x16. 4B. Severe fibroplasia of the stroma accompanied by severe lymphoid depletion of the follicles and metaplasia of the follicular reticular epithelium. Follicles contain large cysts filled with proteinaceous fluid. Lesion score:4. Day 9 pc. H\&E, x16. 4C. Apex of a plica. Severe hyperplasia of the lining epithelium, with the presence of multiple cysts. Lesion score:5. Day 9 pc. H\&E, x40. 4D. Bursal follicles of a control broilers(G2). Lesion score :0.H\&E, x16. 


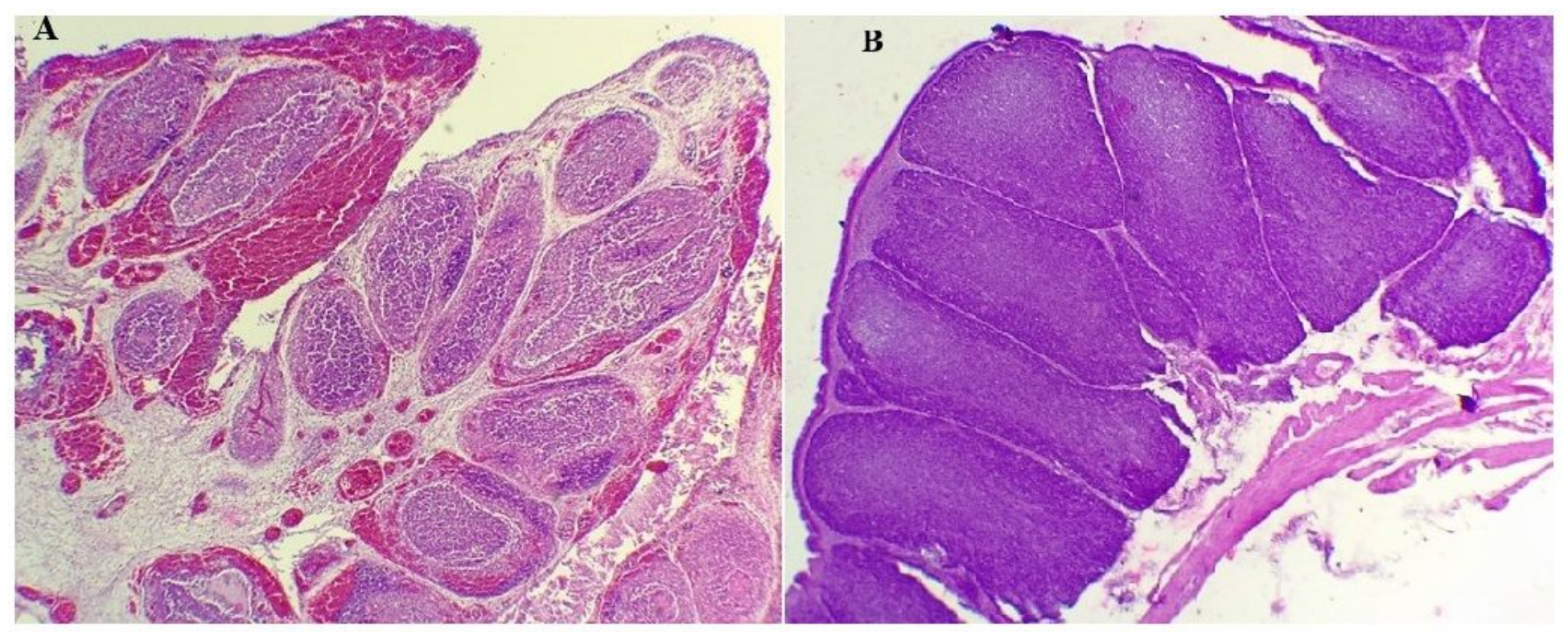

Figure 5

5A. Bursa Follicles of challenged SPF chicken (G3) showing severe haemorrhages and lymphoid depletion. Lesion score :3. Day 3 pc. H\&E, x4. 5B. Intact bursa follicles of unchallenged SPF chicken(G4). Normal structure. Lesion score :0. H\&E, $\mathrm{x} 4$. 


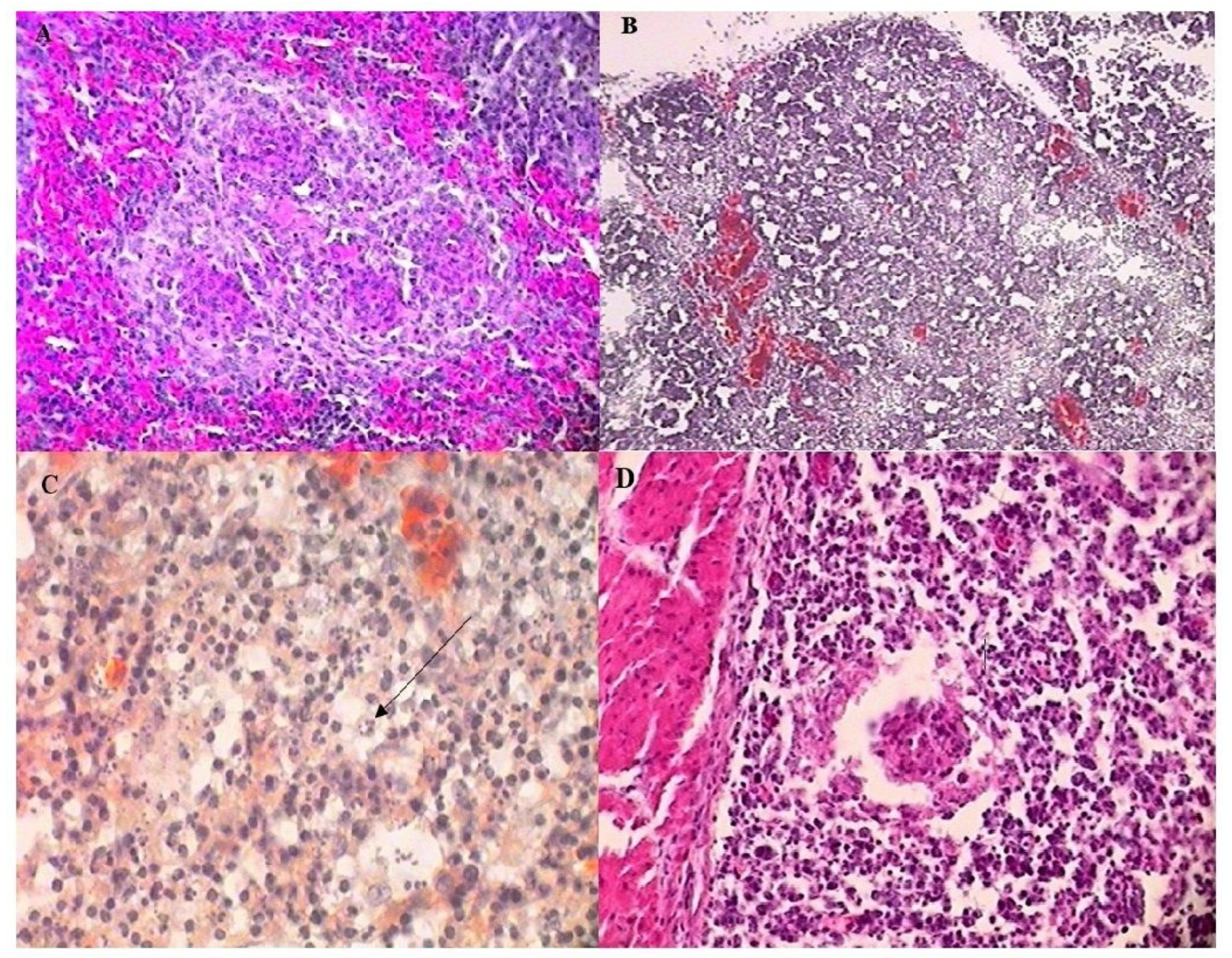

Figure 6

6A. Splenic parenchyma. Severe hyperplasia of the reticular cells, and severe hyperemia of the red pulp. Lesion score : 2. Day 3 pc. H\&E, x40. 6B. Thymic cortex. Severe lymphoid depletion of the cortex with hyperemia and hemorrhages. Lesion score: 3. Day 4 pc. H\&E, x16. 6C. Thymic medulla. Extensive pyknosis, and karyorrhexis (black arrow). Lesion score : 3. Day 4 pc. H\&E,X100. 6D. Lamina propria of a caecal tonsil. Necrosis of a germinal center accompanied by severe lymphoid depletion of the lamina propria. Lesion score: 3. Day 4 pc. H\&E, x40. 

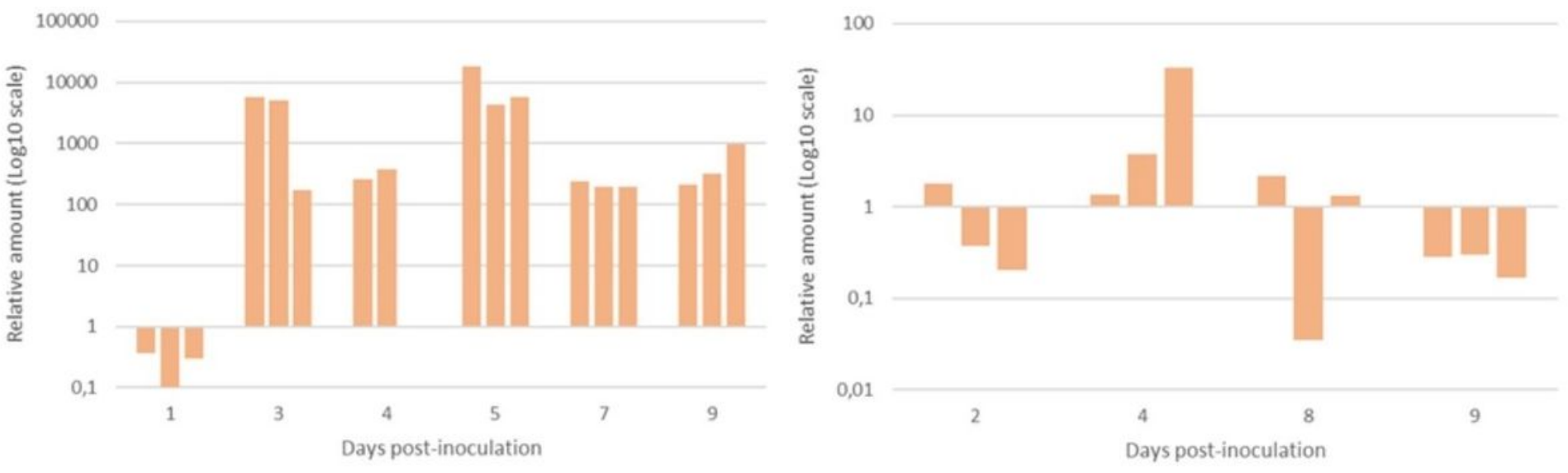

Figure 7

7A. Relative quantification of the viral load in Bursa oragans of challenged broilers(G1). 7B. Relative quantification of the viral excretion in cloacal swabs for challenged broilers(G1). 